\title{
El Sarcófago tardorromano de Tona (Barcelona)
}

\author{
Sergio Vidal Alvarez \\ (Universidad de Barcelona) ${ }^{1}$
}

\section{Resumen}

El presente estudio aborda de manera monográfica la problemática existente en referencia a los fragmentos de sarcórfago tardorromano hallados en 1943 en la localidad barcelonesa de Tona. A pesar de su innegable interés histórico e iconográfico, hasta el momento presente los fragmentos apenas han recibido una atención promenorizada por parte de la comunidad científica. Su estudio nos permite confirmar la existencia de talleres locales de escultura funeraria activos en la zona a caballo entre los siglos IV-V, así como el modo en que la Hispania del momento recibe, asimila y materializa los modelos iconográficos procedentes de Roma.

Palabras Clave. Antigüedad Tardía, Escultura tardorromana, iconografía, sarcófagos cristianos antiguos.

\begin{abstract}
The Present Study focuses on the two Sacorphagus fragments discovered in 1943 in the little Village of Tona (Barcelona). Despite of their historical and iconographical value, until the present day both Fragments were almost ignored by most of the Scholars. The new Study of the Fragments brings now precious Information about the local Production of Sarcophagi int the Roman Hispania between the 4th and 5th Centuries. Furthermore the study give also new light on the process of reception and transformation of iconographical models coming from the city of Rome.

Keywords. Late Antiquity, Late roman Sculpture, Iconography, Ancient Christian Sacophagi.
\end{abstract}

Hoy día son pocas las muestras de la escultura funeraria del período tardorromano que, habiendo sido halladas hace ya unas décadas, carezcan en la práctica de trabajos que les dediquen su atención de manera monográfica ${ }^{2}$. Precisamente esta es la situación en la que se hallan los dos fragmentos de sarcófago tardorromano descubiertos en Tona (Barcelona) en abril

1 Estudio realizado gracias a contar con una Beca de recerca $i$ docència otorgada por la Universitat de Barcelona y a la ayuda del Proyecto de investigación DGICYT PB-981212. Hemos de agradecer también la ayuda prestada para el estudio de las piezas de C. Puigferrat (Museu Municipal de Tona), así como a las constantes sugerencias y apoyo prestados por M. Guardia (Universidad de Barcelona) y V. García Entero (Universidad Autónoma de Madrid).

2 Dan breve noticia de ellos Casassas, E., Tona. Descripció històrica $i$ geogràfica, Barcelona 1943, p. 14; Schlunk, J., "Sarcófagos Paleocristianos labrados en España", Actas del VIII Congreso Internacional de Arqueología Cristiana (Barcelona, octubre 1969), Roma-Barcelona, 1972, p. 214; Pladevall, A., Tona. Mil cent anys d'història, Barcelona, 1990, p. 61; Vidal S., "Escultura funerària", Del romà al romànic, Barcelona, 1999, pp. 224-225. Nosotros mismos hemos tratado de manera más extensa el tema en la publicación local de tirada muy limitada: Vidal, S., "Els fragments de sarcòfag tardorromà de Tona", Llibre de Tona, 1999, pp. 71-79. de 1943 (fig. 1 y 4), en el contexto de las excavaciones de la iglesia de Sant Andreu del Castell y que, desde su creación, conserva el Museo Municipal de esta localidad ${ }^{3}$.

La población de Tona se halla en el sector meridional de la gran depresión natural conocida como la Plana de Vic, a unos $8 \mathrm{~km}$. al sur de

3 Como aparece indicado en el Registro de entradas del Museo Municipal de Tona, el fragmento EC-43 fue hallado el día 23 de abril de 1943 y el fragmento EC-44 al día siguiente, 24 de abril, en el transcurso de las citadas excavaciones, de las que el erudito local F. Vall redactó, con fecha de agosto de 1954, una memoria ilustrada inédita titulada Tona-Sinopsi monogràfica. Cabe destacar que junto a nuestros fragmentos, se conserven en el mismo museo diversas piezas pertenecientes al mobiliario litúrgico de la iglesia prerrománica o de la románica que la sustituyó. Entre las mismas destacan la mesa de altar y restos de sus soportes, incluyendo un pequeño capitel esculpido por las cuatro caras, además de una pequeña arcada, perteneciente al supuesto baptisterio del conjunto. Para estas muestras así como para los templos prerrománico y románico vid. Barral, X., L'Art Pre-romànic a Catalunya, segles IX-X, Barcelona, 1981, p. 224 (con bibliografía); Pladevall, A., Tona. Mil cent anys d'història, Barcelona, 1990, pp. 53-62 


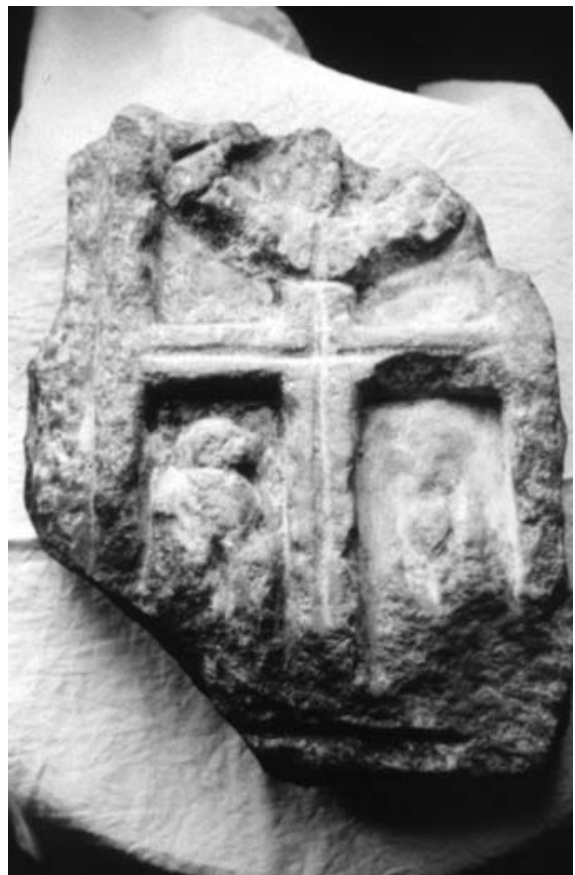

Fig. 1. Fragmento de sarcófago tardorromano de Tona. Tona, Museo Municipal, EC-44 (Foto S. Vidal).

la ciudad de Vic, la romana Ausa, capital de la actual comarca de Osona ${ }^{4}$. Desde finales del siglo II a. C. consta la existencia en la zona de Tona de una red viaria organizada gracias al miliario del Mas del Vilar hoy en el Museo Episcopal de $\mathrm{Vic}^{5}$, mientras que la presencia humana ininterrumpida se prolonga -según los datos conocidos- del siglo III a. C. al III d. C. ${ }^{6}$. Entre esta última fecha y el periodo altomedieval -a partir del siglo IX no faltan los testimonios arqueológicos y documentales- juegan un papel esencial los fragmentos a los que dedicamos el presente estudio, sin duda tardorromanos, especialmente si tenemos en cuenta que las informaciones conocidas hasta el momento corresponden siempre a la vecina Vic, sede espiscopal cuyos obispos aparecen reiteradamente en las listas de asistentes a los concilios eclesiásticos, tanto de ámbito provincial (Tarraconense) como Hispánico (Toledo), de los siglos VI-VII ${ }^{7}$.

4 Caballé, A., "Ciutat d'Ausa (o Auso)", Del romà al romànic, Barcelona, 1999, pp. 92-94, con la principal bibliografía sobre el tema.

5 Rodá, I., Catàleg de l'epigrafia $i$ de l'escultura clàssiques del Museu Episcopal de Vic, Vic, 1989, pp. 48-49, cat. núm. 23, miliario en el que se menciona a M(anius) Sergius, procónsul, datado en torno al 110 a. C.

6 Sanmartí, E., "Un lote de cerámica de barniz negro procedente de Tona (Plana de Vic) (Barcelona)", Pyrenae, 10, 1974, p. 150; Gorges, J. G., Les Villas hispano-romaines. Inventaire et problematique archaeologique, París, 1979, p. 224.

7 Caballé, op. cit., p. 93 y más especialmente Ponisch, P., "Els arquebisbes i bisbes de les diòcesis de la futura

\section{DESCRIPCIÓN Y RESTITUCIÓN DEL ASPECTO ORIGINAL}

El primero de los dos fragmentos (inv. EC-44), que podríamos calificar de "principal” por su iconografía (fig. 1), mide $18,5 \mathrm{~cm}$. de ancho x 22,6 $\mathrm{cm}$. de alto y $6,1 \mathrm{~cm}$. de grosor y muestra, ocupando la práctica totalidad de su superficie, una cruz en forma de tau $(\mathrm{T})$ griega sobre la que aparecen restos de una corona de laurel. A pesar de no conservarse la parte superior, se puede advertir perfectamente cómo en el interior de la corona se hallan restos de un crismón inscrito en ella, del que se aprecia prácticamente todo el palo inferior de la ro griega $(\mathrm{P})$-que visualmente puede parecer una prolongación en formato estrecho de la misma cruz- y los restos del arranque del extremo inferior izquierdo de la ji griega (X). Estamos, pues, ante una Crux Invicta o símbolo de la victoria de Jesucristo sobre la muerte, es decir, de su

Catalunya fins al segle VIII", Del romà al romànic, Barcelona, 1999, p. 33, donde se recogen los seis obispos de Vic documentados de los siglos VI-VII asistentes a los concilios de Tarragona (516), Gerona (517), III de Toledo (589), Barcelona (599), 614 (Egara, actual Terrassa), IV de Toledo (633), VI de Toledo (638), VII de Toledo (653) y XII de Toledo (683). La serie episcopal conocida no se recupera hasta el 885 en época carolingia, por tanto. Para este momento Ollich, I., "Vic. La ciutat a l'època carolingia”, Catalunya a l'època carolingia. Art $i$ cultura avans del romànic (segles IX $i$ X) (Barcelona, 199-2000), Barcelona, 1999, pp. 89-94, con bibliografía. 


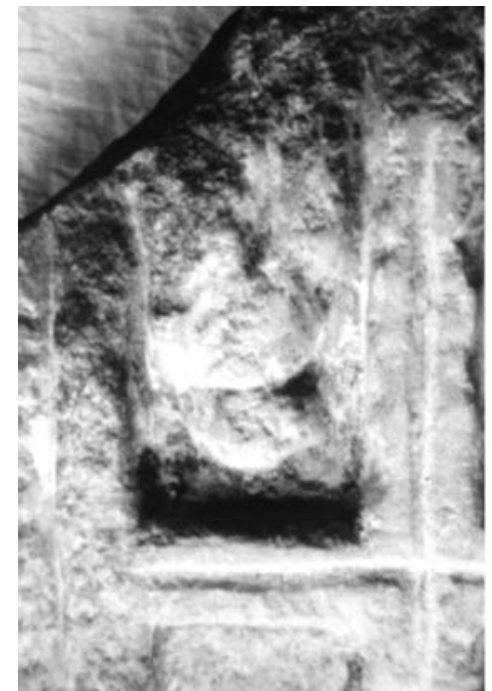

Fig. 2- Detalle de la figura 1, personaje del sector inferior izquierdo. Tona, Museo Municipal, EC-44 (Foto S. Vidal).

resurrección ${ }^{8}$. En la parte inferior del fragmento, bajo el travesaño de la cruz, se pueden observar parcialmente restos de dos figuras de las que sobre todo la de la izquierda conserva todavía buena parte de sus rasgos antropomórficos (fig. 2). Se distingue con claridad la forma de la cabeza de perfil e, incluso, en parte su fisonomía, destacando la nariz y lo que se intuye como los restos de las incisiones que configuran el ojo y la boca. Así mismo, se puede advertir cómo a la derecha del cuerpo hay un elemento que parece haber sido separado de éste por una incisión vertical y que, por tanto, hemos de interpretar, como detallaremos más adelante, como un elemento adyacente a la figura.

Ha tenido menor fortuna, en cambio, la figura del costado opuesto (fig. 3), de la que tan solo podemos percibir parte del volumen del cuerpo, atravesado por dos incisiones a modo de cuña con el vértice hacia abajo. Además, la zona de la cabeza de este segundo personaje nos ha llegado plenamente desfigurada a causa de una pérdida

8 Simbolismo estudiado con cierta profundidad por autores como Baus, K., Der Kranz in Antike und Christentum, Bonn, 1940, espec. pp. 223-230 "Das Triumphkreuz"; Wessel, K., "Cristus Rex. Kaiserkult und Christusbild”, Archäologiscjer Anzeiger, 68, 1953, cols. 118-136, espec. cols. 127-129; id., Die Sieg über den Tod. Die Passion Christi in der frühchristlichen Kunst des Abendlandes, Berlín, 1956, espec. pp. 9-12; Villette, J., La Résurrection du Christ dans l'art chrétien du II au VII siècle, París, 1957, espec. pp. 43-46. Cabe destacar que estos autores insisten específicamente en ésta y no otra interpretación, dejando claro que no estaríamos ante escenas de otra naturaleza como podría ser la del Santo Sepulcro o la del Calvario. En fecha más reciente destacan los estudios sobre el tema de la muerte, anástasis y resurrección de Cristo de Kartsonis, A. D., Anastasis. The making of an image, Princeton, 1986; Grounelle, R., La descente du Chirst aux

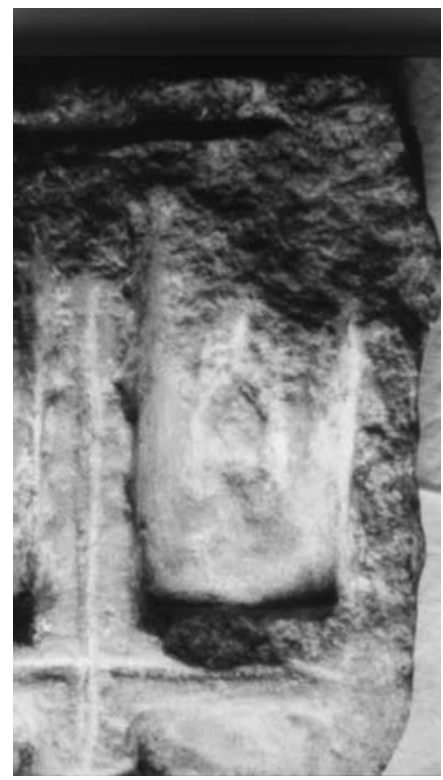

Fig. 3- Detalle de la figura 1, personaje del sector inferior derecho. Tona, Museo Municipal, EC-44 (Foto S. Vidal).

de material, seguramente antigua como lo demuestra el hecho de que -además de muy erosionadala zona tenga una coloración idéntica a la del resto de la pátina externa que recubre el fragmento. A pesar de ello, observando atentamente la pieza desde diversos ángulos y con luz rasante se puede llegar a advertir que, con toda probabilidad, la posición de la cabeza de esta segunda figura era en origen plenamente simétrica a la de la anterior y que, por tanto, dirigia también su mirada hacia el centro del fragmento.

Para interpretar correctamente estas dos figuras, junto con el motivo de la Crux Invicta, hemos de tener en cuenta la serie de sarcófagos de taller romano conocida como "de la Pasión", apelativo que les viene conferido por la importancia que otorgan a las escenas relacionadas con el ciclo de la pasión de Jesucristo ${ }^{9}$. Tomando como ejemplo una de las piezas paradigmáticas de este grupo, el Sarcófago Lateranense 171 conservado en el

enfers. Institutionnalisation d'une croyance (310-550), Études Augustiniennes-Antiquité 162, París, 2000.

9 Para esta serie de piezas, datables entre mediados del siglo IV e inicios del V, vid. especialmente los estudios de Gerke, F., "Die Zeitbestimmung der Passionsarkophage", Archaeologiai Értesitö, LII, Berlín, 1940, pp. 1-130 y XVIII láms., texto bilingüe en húngaro (pp. 1-65) y alemán (67130); Saggiorato, A., I sarcofagi paleocristiani con escene di passione, Bolonia, 1968. A estos estudios cabe añadir de modo especial el sarcófago de Iulia Latronilla que conserva el Bible Lands Museum de Jerusalén, de doble friso y datado en un momento precoz, entre el 330 y el 350, vid., DreskenWeiland, J., Repertorium der Christlich-antiken Sarkophage, II, Italien mit einem Nachtrag Rom und Ostia, Dalmatien, Museen der Welt, Mainz am Rhein, 1998, n. 102, p. 32 y láms. 33 y 34, espec. láms. 33-2 y 33-3, con bibliografía. 


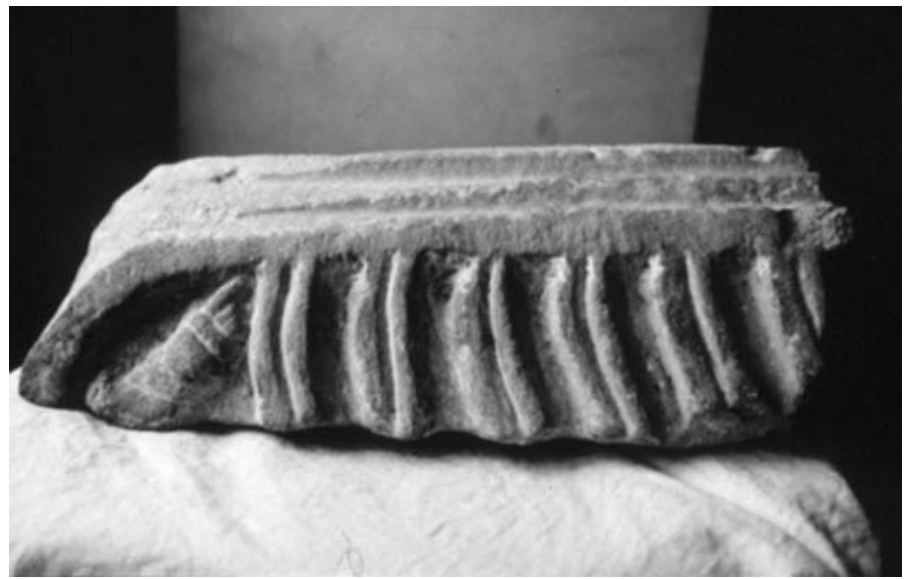

Fig. 4. Fragmento de sarcófago tardorromano de Tona. Tona, Museo Municipal, EC-43 (Foto S. Vidal).

Museo Gregoriano Cristiano de los Museos Vaticanos y datado hacia mediados del siglo IV ${ }^{10}$, se observa cómo el motivo central del mismo (fig. 6) refleja claramente el modelo iconográfico en el que se ha basado directa o indirectamente nuestro fragmento. Así, observamos cómo entre las columnas aparece un crismón inscrito en una corona de laurel sobre una cruz en forma de Tau y dos palomas encima del travesaño picoteando la corona, motivo éste, no obstante, ausente en nuestra pieza. En la parte inferior se representa a dos soldados romanos sentados, uno de los cuales mira fijamente la cruz, mientras que el otro, somnolente, apoya la cabeza sobre su escudo. Parece lógico, por tanto, pensar que ésta es la interpretación que más se ajusta a las dos figuras inferiores de nuestro fragmento, con la salvedad, sin embargo, de que las dos aparecen en actitud de mirar hacia la cruz y al menos una, la de nuestra izquierda, se apoyaría sobre escudo. Respecto al extremo superior, no conservado en nuestro caso, podemos indicar que en ejemplos de la

10 Vid Saggiorato, op. cit., pp. 81-93; Bovini, G.-Branderburg, H., Repertorium der Christlichantiken Sarkophage, I, Rom und Ostia, Wiesbaden, 1967, núm. 49, pp. 48-49, lám. 16, con la principal bibliografía anterior.

11 El motivo del águila en los sarcófagos de la Pasión, con el pico sustentando la corona es especialmente tratado en las obras citadas de Wessel (p. 10) y Villette (p. 43), indicando que se trata de un elemento adquirido de la iconografía romana imperial que no sólo simboliza poder, sino que es también elemento indispensable en las escenas de apoteosis (ascensiones) imperiales. Con todo, la pieza en la que más claramente se puede observar el aspecto físico de esta ave, detallándose toda la cabeza, las alas, etc., se conserva en el Musée de l'Arles Antique (antes Musée lapidaire chrétien), Benoit, F., Sarcophages paléochétiens d'Arles et de Marseille, Supplément a "Gallia" V, París, 1954, núm. 11, p. 38, lám. VIII, 2. Nos parece de gran interés la relación que se plantea entre los soldados de los sarcófagos de la pasión respecto al cuerpo especial crea- serie romana como el Lateranense 171 aparecen las cabezas de las personificaciones del Sol y la Luna en los ángulos y, en el centro, sustentando la corona el pico de un águila con las alas desplegadas insinuadas esquemáticamente en la fornícula de fondo ${ }^{11}$. Evidentmente, no podemos llegar a saber con absoluta certeza si todos estos motivos fueron incluidos o no en nuestra pieza pero el hecho de que falten las palomas picoteando la corona nos hace pensar que estos otros elementos de la parte superior también pudieron haber sido obviados. Es decir, parece factible plantear que el modelo iconográfico romano en el que se fundamenta el fragmento de Tona, no sería exactamente el mismo que el del propio sarcófago Lateranense 171 pero, en todo caso, sí una pieza cercana a él más sintética en cuanto a detalles iconográficos complementarios.

En este sentido, un análisis del resto de sarcófagos conocidos del grupo de la Pasión, conservados mayoritariamente en Roma y, en menor cantidad, en Arlés, nos lleva a poder establecer

do por el emperador Constantino destinado a la custodia del Labarum imperial, el aspecto del cual era completamente idéntico al crismón de nuestros sarcófagos. Para esta cuestión vid. Grabar, A., L'epereur dans l'art byzantin, Estrasburg, 1936, (reimp. Londres, Variorum Reprints, 1971), pp. 242-243; Gerke, op. cit., pp. 74-75; Wessel, op. cit., p. 11; Villette, op. cit., p. 45, entre otros. Un dato más que cabe destacar con respecto a esta última cuestión es la existencia de lucernas en las que se ilustra precisamente el mencionado cuerpo de guardia, representándose a dos soldados en acción de flanquear el Labarum constantiniano con la inscripción "In hoc vinci", vid. Paleani, M. T.-Liveriani, A. R., Lucerne paleocristiane conservate nel Museo Oliveriano di Pesaro, I, Roma, 1984, p. 96, según dibujo extraído de la obra de Passeri, J. B., Lucernae veterum christianorum ex Museo Jo. Baptistae Passerii Pisaurensis selectae et notis eiusdem illustratae anno MDCCLXXII feris liberalibus, ms. 286), lám. XVI, n. 3. 


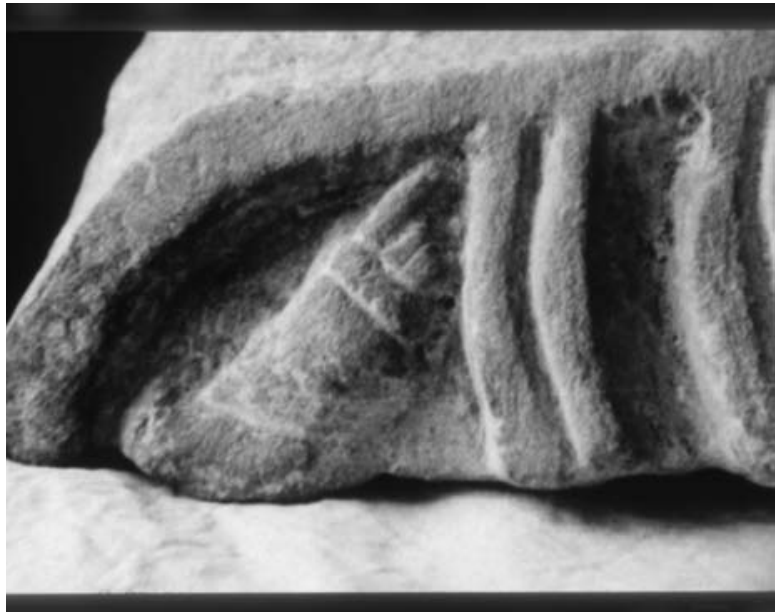

Fig. 5. Detalle de la figura 4. Tona, Museo Municipal, EC43 (Foto S. Vidal).

un paralelo relevante, el Lateranense 170 (fig. 7). Se trata de un fragmento de sarcófago hoy en el Museo Gregoriano Profano, en el que precisamente los dos soldados aparecen de pie y mirando a la cruz, en este caso una cruz-crismón gema$\mathrm{da}$, sin la corona de laurel ni las palomas, pero con los dos personajes apoyándose sobre sus escudos respectivos. A la izquierda se observa el inicio de un campo de estrígiles, por lo que queda claro que la escena principal central no aparece flanqueada por otros episodios o personajes, como es habitual en el resto de sarcófagos de la Pasión ${ }^{12}$. Esta peculiaridad del Lateranense 170 habrá de ser tenida en cuenta más adelante, cuando intentemos reconstruir el aspecto original de nuestra pieza.

El segundo fragmento de Tona (fig. 4), con el número de inventario $\mathrm{EC}-43$, mide $28,5 \mathrm{~cm}$. de largo $\mathrm{x} 7,5 \mathrm{~cm}$. de alto y $7,8 \mathrm{~cm}$. de grosor, y se trata del ánglulo superior izquierdo de la cara frontal de un sarcófago. Ciertamente, no nos ofrece la misma riqueza iconográfica del fragmento anterior ya que posee tan solo restos de los extremos superiores de seis estrígiles y, hacia la izquierda, lo que parece ser la extremidad superior de una figura humana. Se puede advertir únicamente la mano del personaje con el dedo índi-

12 Para el Lateranense 170 vid. Saggiorato, op. cit. p. 142; Bovini-Brandenburg, op. cit., núm. 82, p. 69, lám. 24, datado a principios del siglo $\mathrm{V}$ por el tipo de talla. Por otra parte, poca ayuda nos aportan el único ejemplar de sarcófago de la Pasión de taller romano que conocemos en la Península Ibérica, el de Valencia, ya que pertenece a otro estadio iconográfico dentro de la evolución de estas piezas (Gerke, op. cit., p. 110), mostrando un ciervo y un cordero flanqueando la cruz, que simbolizan a San Pedro y San Pablo o a los fieles, pero en ningún caso a los soldados. Para esta pieza (de manera errónea obviada por Saggiorato) véase especialmente Sotomayor, M., Sarcófagos

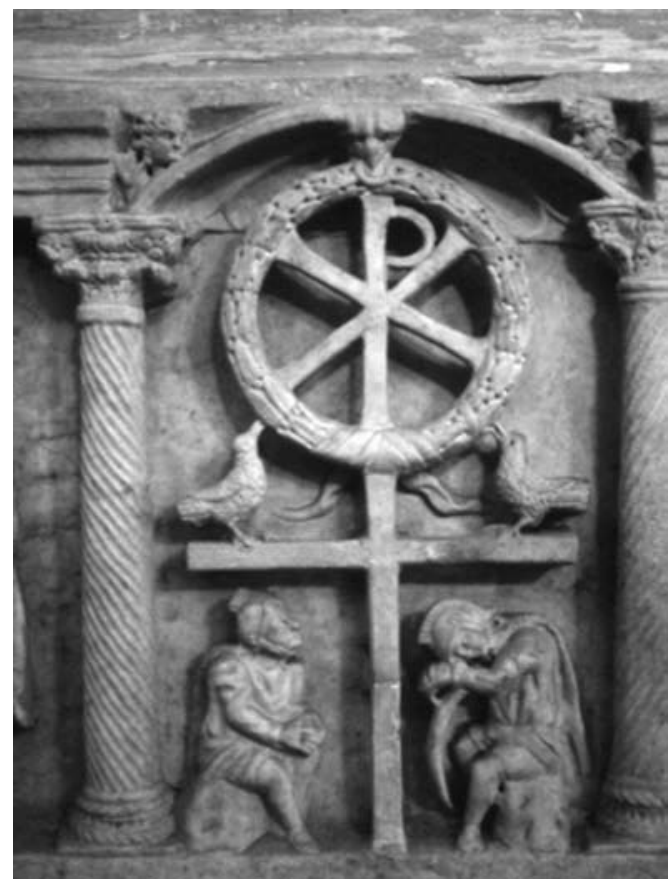

Fig. 6. Detalle de la fornícula central del Sarcófago Lateranense 171. Musei Vaticani (Museo Gregoriano Cristiano), Lat. 171 (Foto S. Vidal).

ce extendido y parte de la manga (fig. 5). La posición del índice y la dirección a la que se dirige el brazo, hacia arriba y a la derecha, hacen reducir en gran parte el número de posibles lecturas iconográficas, quedando descartadas, entre otras, las escenas en las que se incluye la mano derecha de Dios Padre o Dextera Domini saliendo del cielo -el Sacrificio de Isaac, Moisés recibiendo la Lei en el Sinaí, etc.-, o aquellas en las que aparecen orantes con los brazos alzados y las palmas de las manos abiertas -Daniel en el foso de los leones, los tres hebreos en el horno de Babilonia ${ }^{13}$, etc.-. Por otra parte, el reducido espacio donde tendría que encajar el resto del cuerpo de la figura nos indica que estamos ante un único personaje dispuesto de perfil. Por todo ello y según el contexto iconográfico en el que -como intentaremos demostrar seguidamente- se inscribiría esta figura, nos parece plausible proponer que se trata de la representación de un apóstol que hallaría su

romano-cristianos de España. Estudio iconográfico, Granada, 1975, pp. 207-209 y, más recientemente, Soriano R., "Sarcófago del ciclo de la Pasión llamado, de San Vicente", La luz de las imágenes (Valencia, 1999), Valencia, 1999, vol. II-1, pp. 40-41, cat. n. 4, con bibliografía hasta la fecha.

13 Sobre este tema vid. nuestro reciente estudio Vidal, S. "Problemas en torno a la iconografía del libro de Daniel en la escultura hispánica de los siglos IV-VII", Madrider Mitteilungen, 43, 2002, pp. 220-238. 


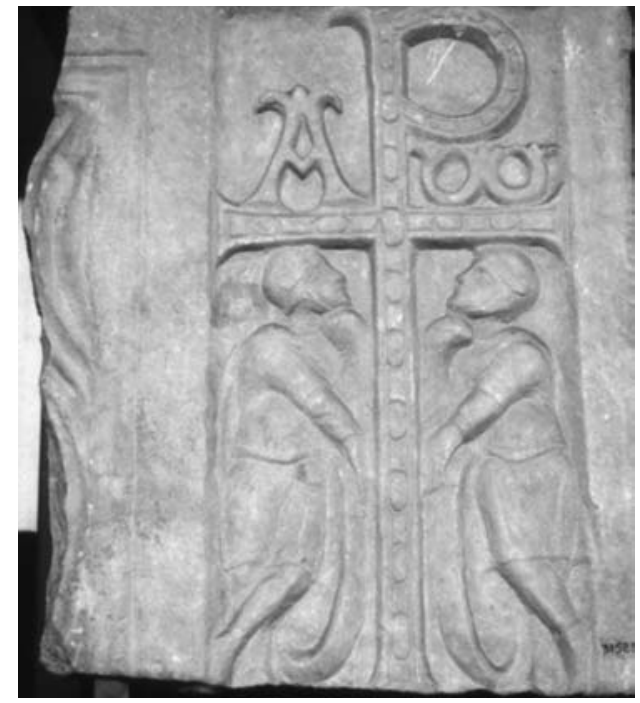

Fig. 7. Detalle de la fornícula central del Sarcófago Lateranense 170. Musei Vaticani (Museo Gregoriano Cristiano), Lat. 170 (Foto S. Vidal).

pareja simétrica o pendant compositivo e iconográfico, en el extremo contrario, perdido en nuestro caso.

Cabe remarcar que estos dos personajes, tal vez Pedro y Pablo, estarían flanqueados por un lado por sus respectivos campos de estrígiles y, por otro, por la moldura de enmarcamiento que rodearía toda la pieza. Al mismo tiempo, las dos figuras estarían lógicamente relacionadas con una escena central que, en este caso, ha de corresponder con toda probabilidad al fragmento anterior con Crux Invicta a pesar de la notable diferencia de grosor existente entre ambas piezas. En efecto, a pesar de que dicha diferencia -superior a $1,5 \mathrm{~cm}$.- sea suficiente como para plantear que los fragmentos no pueden pertenecer a un mismo sarcófago, es también cierto que tan sólo el fragmento estrigilado (fig.4) parece conservar el grosor original total y, por tanto, parte del borde superior y de la cara interna de la pieza. Por contra, el primer fragmento (fig. 1) no nos proporciona información alguna sobre

14 Bovini-Brandenburg, op. cit. núms. 224, 229, 240, 245 (con estrías), 670, 678, 682, 684, 738, 828. Benoit, op. cit., núms. $76,80,82,83,84$, y la pieza de la p. 62 , nota 3 . Mención aparte merecen las piezas de taller local marsellés del siglo V, como las núm. 111 a 114, de la misma obra de Benoit, todos ellos sin estrígiles.

15 Saggiorato, op. cit., pp. 138-142.

16 Para el ejemplar de la Catacumba de San Sebastiano vid. Bovini-Brandenburg, op. cit., núm. 224, pp. 133-134, lám. 51. En otras piezas de taller romano los apóstoles de los extremos sí aparecen dispuestos simétricamente y con los brazos levantados. Ibid. núms. 229, 670, 684, 738 y 828, así como en algunos de los ejemplares de estos mismos talleres que recopila Dresken-Weiland, op. cit., núms. 113 (Monza), sus límites inferior ni, menos todavía, superior, al margen de que su cara interna parece tener indicios de haber estado rebajada a posteriori.

Entre los paralelos para la disposición compositiva que proponemos para nuestro ejemplar (fig. 10) contamos, nuevamente dentro del corpus de sarcófagos de taller romano de la segunda mitad del siglo IV e inicios de $\mathrm{V}$, con un buen número de ejemplares donde aparece el mismo esquema compositivo, esto es, centro ocupado por la escena principal, a los lados los respectivos campos de estrígiles y, finalmente, en los extremos, las dos figuras aisladas alzando el brazo -en mayor o menor grado según los casos- que son en casi una veintena de ejemplos (fig. 8), tal y como planteamos para la pieza de Tona, apóstoles ${ }^{14}$. Especialmente en un sarcófago romano de la Catacumba de San Sebastiano, datado en el último cuarto del siglo IV (fig. 9), contamos con una disposición formal muy parecida a la del nuestro, diferenciándose en algunos elementos como la sustitución de los soldados por dos apóstoles bajo la Crux así como la posición no alzada de los brazos de los apóstoles de los extremos. Estas diferencias, lejos de contradecir nuestra propuesta, se inscriben perfectamente dentro de las variantes tipológicas existentes en el grupo de sarcófagos "de la Pasión”, especialmente en los denominados "de Venera-ción apostólica" ${ }^{15} \mathrm{y}$, cómo no, dentro del margen de libertad compositiva existente en los talleres escultóricos de estos momentos ${ }^{16}$.

Por otra parte, cabe añadir que este segundo fragmento (fug. 4) ha llegado hasta nosotros en un estado de conservación bastante mejor que el anterior (fig. 1), ya que al contrario que en aquel, la erosión de la superficie ha sido mínima, proporcionándonos así una valiosa información en lo referente a los aspectos técnicos y formales. Es decir, tenemos un tipo de talla de la piedra basada en la incisión directa de la superficie dejándola en dos niveles o planos de profundidad neta-

143 (Palermo), 146 (Split), 148 (Tolentino), y los fragmentos 106 (Roma, San Lorenzo fuori le mura), 110 (Roma, Basílica anonima della Via Ardeatina), 114 (Suiza, colección privada) y 153 (Poreč). Respecto a los ejemplares conservados en Arlés, los más interesantes para nosotros serían los núms. 82-84, pp. 62-63, lám. XXIX de la obra citada de Benoit, datables hacia finales del siglo IV, especialmente el núm. 82 por ser en el que, además, los apóstoles aparecen con un brazo extrendido señalando hacia Cristo. En las Galias destaca junto a un campo de estígiles y en centro Cristo y un apóstol con roleos de vid detrás. Griesheimer, M., "Sarcophage à strigiles", Premiers temps chrétiennes en Gaule méridionale, Lyon, 1986, p. 72, n. 123, p. 72. 


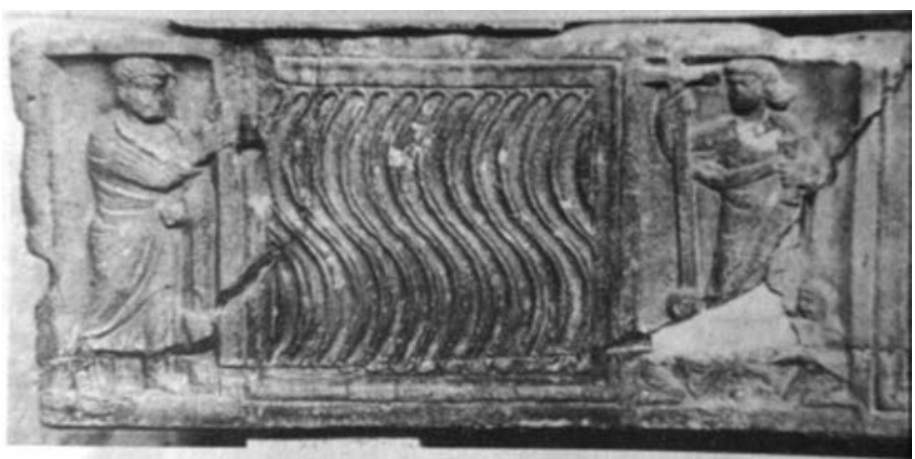

Fig. 8. Sarcófago de Arlés. Arlés, Musée de l'Arles Antique (Benoit, F., Sarcophages paléochétiens d'Arles et de Marseille, Supplément a "Gallia" V, París, 1954, lám. XXIX,1, n. 82).

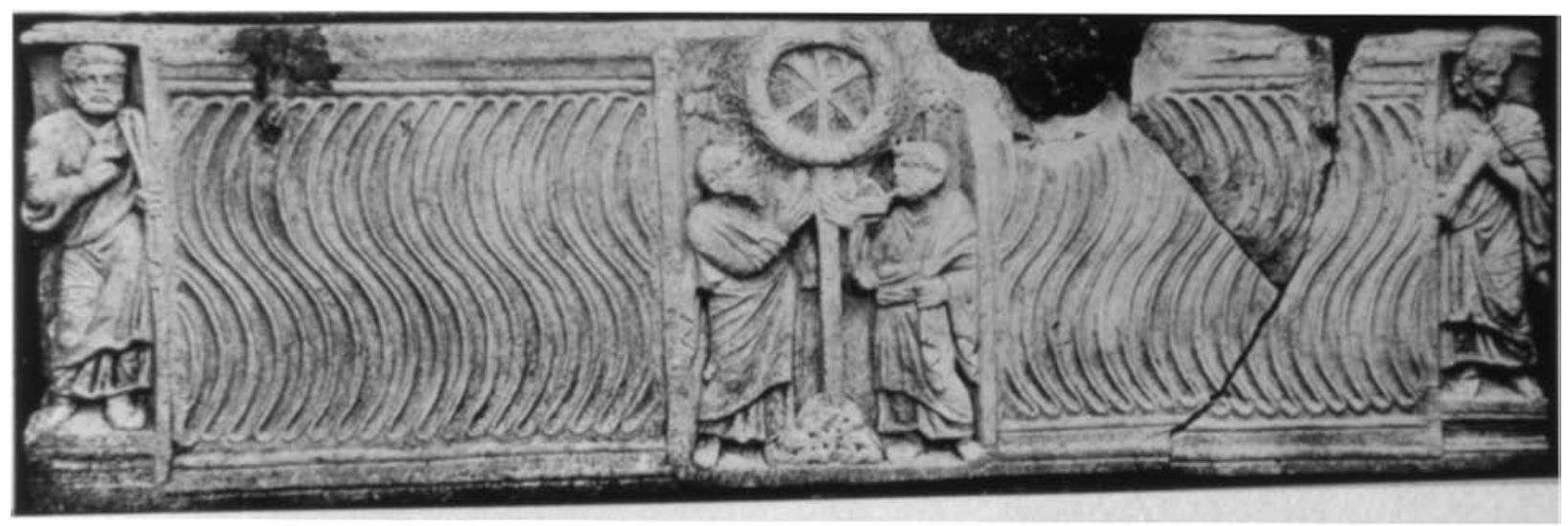

Fig. 9. Sarcófago del Cimitero di San Sebastiano. Roma, Catacomba di San Sebastiano (Bovini, G.-Brandenburg, H., Repertorium der Christlich-antiken Sarkophage, I, Rom und Ostia, Wiesbaden, 1967, lám. 51, n. 224).

mente diferenciados, sin prácticamente modelar ninguno de los volúmenes. Además, se observa cómo la decoración estrigilada es claramente peculiar ya que se aleja, de manera notoria, del tipo predominante en toda la escultura funeraria mediterránea de los siglos IV-VI. Efectivamente, a pesar de su estado fragmentario, se puede observar cómo nos encontramos ante un tipo de estrígiles de curvatura muy suave y acanaladuras toscas, con los extremos superiores configurados por simples formas cuadrangulares. En todo caso, por sencillos que sean, se trata de estrígiles siendo evidente que no estamos ni ante simples estrías verticales, ni tampoco ante los típicos

17 Para estas piezas, son de consulta obligada las actas del Coloquio Les sarcophages d'Aquitaine, publicadas en Antiquité tardive. Revue internationale d'histoire et d'hitoire et d'archéologie (IV ${ }^{e}-V I I I^{e}$ s.), I, 1993. Es, sin embargo, especialmente reseñable el trabajo de Briesenick, B., "Typologie und Chronologie der Südwest-gallischen Sarkophage", Jahrbuch des Römisch-Germanischen Zentralmuseums Mainz, 9, 1962, pp. 76-182.

18 Efectivamente, dadas las dimensiones de los fragmentos consevados, la altura máxima de toda la pieza no llega a los $25 \mathrm{~cm}$., mientras que la anchura devió de ser de poco menos de $50 \mathrm{~cm}$. (30 cm. del fragmento estrigilado y 20 cm. del fragmento con Crux invicta). Haciendo un cálculo chevrons en zig-zag de los sarcófagos de taller sudgálico $^{17}$.

Respecto al formato de la pieza en su estado original calculamos que, en función de las reducidas dimensiones de los fragmentos conservados, no alcanzaría los $130 \times 40 \mathrm{~cm}$. y que, por tanto, el sarcófago debió corresponder a un niño ${ }^{18}$. Por otro lado, como nos muestra la parte superior del segundo fragmento (fig. 4), tendría en origen las esquinas redondeadas -al menos las superiores- y poseería, en la parte superior del frente, dos molduras sobrepuestas que le conferirían un aspecto "escalonado" completamente

estimativo, la altura total pudeo perfectamente llegar a los $30 / 35 \mathrm{~cm}$., pero difícilmente sobrepasaría los $40 \mathrm{~cm}$., mientras que la longitud, teniendo en cuenta la falta de toda la parte derecha, estimamos que podría llegar a 110 $\mathrm{cm}$. $(45 \mathrm{~cm}$. del costado izquierdo, $20 \mathrm{~cm}$. del centro y 45 $\mathrm{cm}$. del costado derecho simétrico al izquierdo). Estas medidas aproximadas de $110 \times 30 / 35 \mathrm{~cm}$. en ningún caso se acercan a los $190 / 220$ x 62/75 cm. que, normalmente, tienen las piezas "convencionales", en cambio, son cercanas a los 117 x $41 \mathrm{~cm}$. que tiene el sarcófago Amatller del Museu d' Arqueologia de Catalunya-Barcelona, Del romà al romànic, ob. cit., pp. 218-219, con bibliografía. 


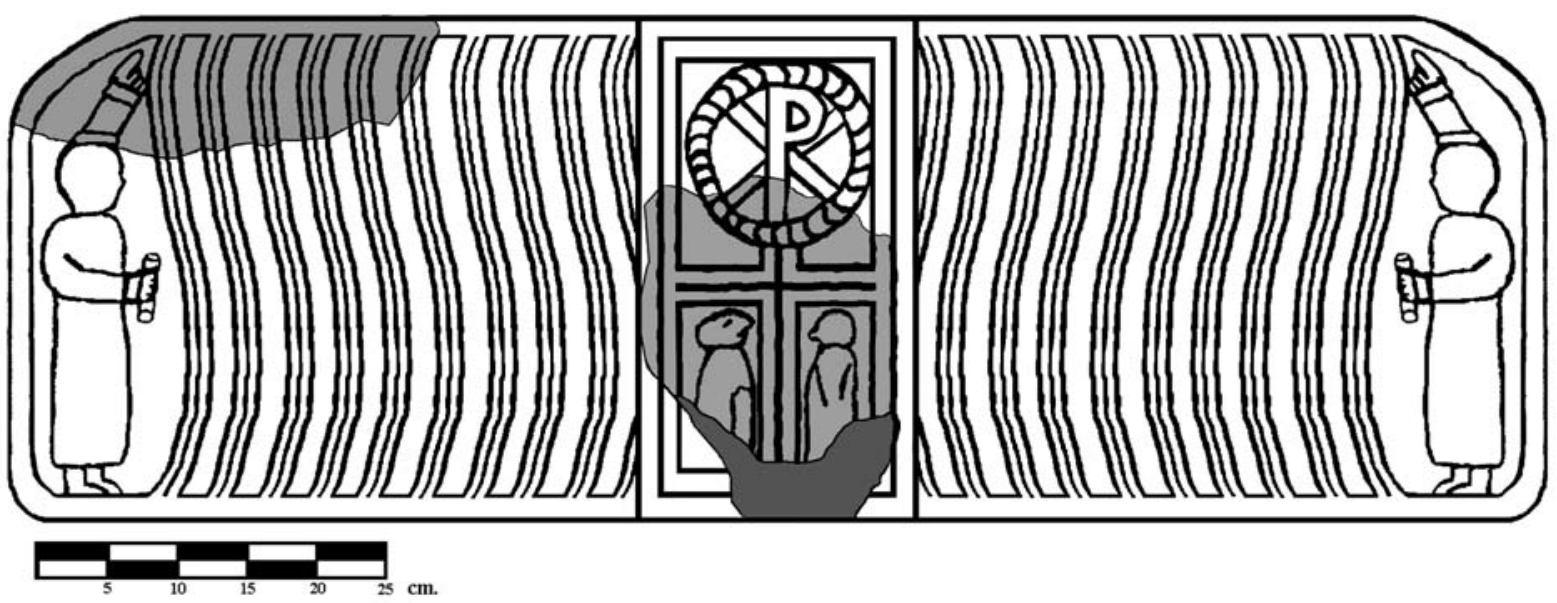

Fig. 10. Esquema de restitución hipotética de la cara frontal del sarcófago tardorromano de Tona (S. Vidal).

original y para el que, todavía, no conocemos ningún otro paralelo exacto. Además, al tener la superficie de la cara posterior totalmente lisa, no parece del todo imposible pensar que pudiera tratarse de un frontal de sarcófago y no de una caja completa. Llegamos a esta conclusión por el hecho de que este reverso no muestre indicio alguno de la existencia del ángulo de transición entre la cara frontal y la lateral izquierda.

\section{Procedencia y Cronología}

Según lo expuesto hasta ahora, parece lógico pensar que, a pesar de que la iconografía tenga un claro punto de referencia respecto a las piezas de taller romano de la segunda mitad del siglo IV, ni el estilo, ni el formato, ni la ejecución de nuestro sarcófago apuntan en el mismo sentido. Es decir, desde nuestro punto de vista deberíamos hablar de una producción local o, a lo sumo, del sur de la Gallia y, más concretamente, dentro de lo que genéricamente se conoce como "Escuela de Aquitania"19. En su momento Schlunk ya planteó esta última posibilidad, matizando que si no era ésta la procedencia de la pieza al menos podría ser la de los artesanos que la ejecutaron. Efectivamente, puede advertirse un cierto punto de confluencia respecto a las fórmulas de algunos de estos sarcófagos "aquitanos" como, por ejemplo, la disposición simétrica de

\section{Vid. supra nota 11.}

20 Para poner de relieve esta relación Schlunk cita concretamente las piezas de Martres-Tolosane que publica Boube, J., "Les sarcophages paléochrétiens de Martres-Tolosane", Cahiers Archèologiques, IX, 1957, pp. 33-72. Por nuestra parte, preferiríamos tener presentes ejemplos como los núms. 1, 2, 10, 11, 19 y 35 del estudio citado de Briesenick, mostrando apóstales en los extremos, de per- los apóstoles y, en algunos casos, hasta cierto punto, el tipo de talla ${ }^{20}$. Precisamente el aspecto de la talla constituye el motivo por el que, sin dejar el sur de la Gallia -aunque más hacia el este-, nosotros mismos indicamos la relación existente entre nuestros fragmentos y alguna de las obras más tardías de la producción local de la Provenza, especialmente el sarcófago de Lurs. Se ha de entender, sin embargo, que esta relación afectaría simplemente a ciertas soluciones coincidentes, materializadas en algunos elementos concretos como la cruz y, en cierta medida, las acanaladuras pero sin que en ningún caso esto constituya una relación directa entre ambas piezas ${ }^{21}$. Pensamos, por tanto, que este tipo de relación coincidente es la que también se da respecto a los sarcófagos "aquitanos" ya que en ellos no conocemos ningún ejemplar lo suficientemente cercano al nuestro ni en iconografía, ni en estilo, ni en formato como para poder plantear esta procedencia para los fragmentos, taller o escultor que los realizó.

Con todo, para poder confirmar plenamente la hipótesis del origen local de las piezas de Tona, sería necesario llevar a cabo un exhaustivo análisis petrográfico. A pesar de que, en principio, es bastante evidente que ambos fragmentos son del mismo tipo de piedra, no podemos afirmar que ésta sea arenisca del Brull, de tonalidades rojizas,

fil y, a veces, también señalando hacia el centro -hacia Cristo-. La datación de estos ejemplares se inscribe siempre dentro del siglo VI.

21 Para la pieza de Lurs, datada hacia los siglos VII-VIII, vid. Benoit, F., "Le sarcophage de Lurs en Provence", Cahiers Archèologiques, X, 1959, pp. 27-70, espec. figs. 10 y 14 . 
como en su momento afirmaron Schlunk -según la información que al respecto le proporcionó $\mathrm{F}$. Vall- y Pladevall. Tal y como los podemos observar hoy día, los fragmentos aparecen recubiertos de una homogénea pátina que les confiere un aspecto externo grisáceo. Sin embargo, las zonas que han sufrido roturas posteriores al descubrimiento -carentes de pátina- parecen confirmar que no se trata de arenisca sino, más bien, piedra calcárea, siendo por ello improbable que proceda del Brull. A pesar de todo, no hay tampoco indicios para afirmar que la piedra sea foránea a la propia Plana de Vic, donde no faltan las afloraciones de este tipo de calcáreas ${ }^{22}$.

Se puede proponer, además, que el comitente original de la pieza devió ser, con toda probabilidad, un terrateniente local que eligió como lugar final para el descanso de uno de sus hijos una pieza hecha a imitación de los referentes más lujosos de los que tenía constancia: los sarcófagos de mármol con decoración figurada importados de Roma. Seguramente a causa de no estar en disponibilidad de adquirir directamente una de estas piezas, ya sea por falta de una distribución comercial organizada o, simplemente, por estar fuera de sus posibilitades económicas, nuestro comitente optaría por mandar hacer una "copia" -entendida en sentido coetáneo del términosobre un material y por una mano de obra locales. Un paralelo hispánico para el fenómeno que acabamos de mencionar nos lo proporciona el mausoleo de las Vegas de San Antonio, cerca de Puebla Nueva (Toledo), cuyo propietario, un latifundista de elevado poder adquisitivo y alto nivel socio-cultural, manda construir un mausoleo con cripta para ubicar su sarcófago que, en este caso, sigue de cerca las corrientes de moda en la Constantinopla del momento -finales del siglo IV-principios del V-. Se trata del célebre sarcófago con Cristo entronizado flanqueado por los doce apóstoles, descubierto in situ a finales del siglo XIX y actualmente conservado en el Museo

22 Vid. Busquets, P. - Domínguez, A. - Vilaplana, M., Geologia d'Osona, Barcelona, 1979, espec. pp. 24-28; Reguant, S. - Busquets, P. - Vilaplana, M., Geologia de la Plana de Vic, Vic, 1986, espec. pp. 15, 23, 34-39. Hemos de agradecer en este punto la viosa ayuda proporcionada por la geóloga local N. Capdevila, informándonos de que, realmente, no se trata de arenisca del Brull sino de una calcárea del Muschelkalk (era secundaria, período triásico), con bastante probabilidad de procedencia local (zona de Centelles?).

23 Para el sarcófago de Puebla Nueva y el mausoleo en el fue hallado vid. Schlunk, ob. cit., pp. 204-208; Schlunk, Th., Hispania Antiqua. Die Denkmäler der frühchristlichen und westgotischen Zeit, Mainz am Rhein, 1978, pp. 129-131, con bibliografía.
Arqueológico Nacional de Madrid ${ }^{23}$. Lamentablemente en Tona no consta la existencia de un paralelo arquitectónico de estas característica puesto que, tal y como revelan las últimas investigaciones, la llamada "torre del Castell" no parece tratarse de un mausoleo turriforme de época romana sino, más probablemente, de una construcción defensiva -torre de vigilancia- altomedieval ${ }^{24}$. En cambio, gracias a algunos hallazgos cerámicos de carácter puntual, sí se cuenta, al menos, con documentación arqueológica al respecto de la presencia de algún posible establecimiento rústico, tal vez una villa ${ }^{25}$.

No podemos precisar, lógicamente, en qué momento nuestra pieza quedaría fracturada para ser, finalmente, removida junto con otros muchos materiales de diversas épocas en la nivelación del terreno que tuvo lugar para la construcción de la iglesia románica de Sant Andreu del Castell. Simplemente podemos sugerir como hipótesis la posibilidad de que, junto con el resto de materiales exhumados durante las excavaciones de 1943, nuestro sarcófago, seguramente fragmentado ya desde hacía tiempo, podría haber formado parte de la decoración del templo prerrománico, especialmente el fragmento con la Crux Invicta -como recordaremos el más erosionado de los dos- $y$, por otra parte, el único con un motivo -la cruz- aún perfectamente reconocible.

Finalmente, para la datación de los fragmentos proponemos de manera genérica una cronología dentro de la primera mitad del siglo $\mathrm{V}$, en relación con las dataciones que nos proporcionan sus evidentes lazos iconográficos de origen romano. Entendemos que, como copia, tienen que ser lógicamente posteriores a su modelo, teniendo presente que éste pudo haber estado ya plenamente configurado en la Roma del último tercio del siglo IV. La cronología propuesta puede ser, además, relacionada con la que nos ofrece buena parte de las piezas tardías conoci-

24 Bolós, J., "El Castell de Tona, un edifici singular", Llibre de Tona, 1997, pp. 81-88, donde se fecha esta construcción, de $8 \mathrm{~m}$. de altura, en torno al año 900 .

25 Se trata de un conjunto cerámico compuesto por cerámica de barniz negro de mediados del s. III a. C., cerámica companiense A y B de la segunda mitad del siglo II a. C., sigillata sudgálica del s. I d. C. y sigillata clara de finales del s. II - inicios del s. III d. C., de lo que se deduce una ocupación de la supuesta villa entre el s. III a. C. y el III d. C. Vid. Sanmartí, op., cit., passim; Gorges, op. cit., p. 224.

26 Para las mismas y su principal bibliografía vid. Vidal, Del romà al romànic, op. cit., pp. 221-224 
das de la escultura funeraria tardorromana de la Tarraconense, entre las que destacan, indudablemente, el grupo hallado y conservado en Tarragona encabezadas por el sarcófago de Leucadius y el llamado sarcófago "de los Apóstoles", habitualmente datados entre los años 410-469 ${ }^{26}$. Hemos de recordar, sin embargo, que estos últimos son considerados obra de los talleres de Cartago y, por tanto, desde el punto de vista hispánico, productos foráneos adquiridos por vía comercial que nos revelan la existencia de una actividad entre Cartago y Tarraco similar a la llevada a cabo en el siglo anterior con respecto a Roma. Por lo tanto, hasta la fecha y en espera de futuros hallazgos que ayuden a completar nuestros conocimientos, los fragmentos de Tona son los únicos ejemplos de época tardoantigua que demuestran la existencia, en la Tarraconense, de una producción local de escultura de sarcófagos en un momento posterior al año 400. 